\title{
Targeted treatment in viral associated inflammatory cardiomyopathy
}

\author{
Ahmad Amin ${ }^{1}$, Sepideh Taghavi ${ }^{1}$, Maryam Chenaghlou ${ }^{2}$, Elahe Zare ${ }^{3}$, Monireh Kamali ${ }^{4}$ \\ and Nasim Naderi ${ }^{4}$ \\ ${ }^{1}$ Rajaie Cardiovascular Medical and Research Center \\ ${ }^{2}$ Tabriz University of Medical Sciences \\ ${ }^{3}$ Yazd Cardiovascular Research Center, Shahid Sadoughi University of Medical Sciences, \\ Yazd, Iran \\ ${ }^{4}$ Iran University of Medical Sciences
}

April 10, 2021

\begin{abstract}
Though generally self-limited, viral myocarditis can lead to acute cardiac failure or chronic dilated cardiomyopathy. We describe three cases of human herpes virus 6 (HHV6) associated -myocarditis unresponsive to conventional therapies, with detection of HHV-6 evidences and initiation of antiviral treatment, we observed significant improvement in clinical status of patients.
\end{abstract}

\section{Hosted file}

Targeted treatment in HHV 1.pdf available at https://authorea.com/users/407083/articles/

517491-targeted-treatment-in-viral-associated-inflammatory-cardiomyopathy 